\title{
A DIMENSÃO HUMANA DO HERÓI NA GUERRA DO PARAGUAI (1864-1870)
}

\author{
Gustavo Ribeiro Capibaribe \\ Doutorando em Desenvolvimento Local- PPGDL-UCDB-MS \\ gustavocapibaribe@outlook.com \\ Luiz Jeha Pecci de Oliveira \\ Mestrando em Desenvolvimento Local- PPGDL-UCDB-MS \\ luizpecci97@gmail.com \\ Wilson Cardoso de Sá \\ Doutorando em Desenvolvimento Local- PPGDL-UCDB-MS \\ Wilson_cardoso@hotmail.com \\ Heitor Romero Marques \\ Doutor em Desenvolvimento local. PPGDL-UCDB-MS \\ heiroma@ucdb.br
}

\begin{abstract}
RESUMO
O presente trabalho tem o objetivo de analisar um novo conceito sobre o herói e o heroísmo, inserindo-o na análise da Guerra do Paraguai (1864-1870), pontuando a dimensão humana da figura sobre a qual se aplica esse conceito. Valendo-se de bibliografia diversa, estabelecer-se-á a definição de "herói" como sendo o indivíduo que, impelido pela virtude na busca e defesa de um sentido para sua vida, sacrifica-se sob um ideal de serviço ao próximo, reabsorvendo e transcendendo as suas circunstâncias. Então, será trazido o contexto da Guerra do Paraguai, mostrando-a como um importante conflito sul-americano, de modo a compreendê-la também como um grande berço de indivíduos com características heroicas. Por fim, será feita uma análise sobre a dimensão humana da figura construída, e como ela se insere no contexto bélico do conflito narrado. $O$ artigo conclui que os heróis na Guerra do Paraguai foram pessoas comuns que, diante de grande sofrimento, apresentaram um comportamento acima da média esperada para a sociedade, realizando atos extraordinários, de modo que se identifica o heroísmo na pessoa capaz de apresentar à coletividade a esperança e o amor desejados em caso de situações adversas, como nesse exemplo histórico. Quanto à metodologia, este artigo se valeu do método hipotético-dedutivo do procedimento histórico.
\end{abstract}

Palavras-chave: Herói; heroísmo; circunstâncias; Guerra do Paraguai; dimensão humana. 


\section{ABSTRACT}

\section{THE HERO'S HUMAN DIMENSION AT THE PARAGUAYAN WAR (1864-1870)}

The current work has the objective of analyze a new concept about the hero and heroism, inserting it in the analysis of the Paraguayan War (1864-1870), pointing the human dimension of the figure that this concept applies itself. Utilizing diverse bibliography, it will be established the definition of "hero" as being the individual which, impelled by virtue in the search and defense for a meaning for his life, sacrifice himself under an idea of serving the others, reabsorbing and transcending his circumstances. Then, it will be brought the context of the Paraguayan War, showing it as an important South American conflict, to comprehend it also as a big cradle of individuals with heroic characteristics. Lastly, it will be made an analysis about the human dimension of the figure built, and how it inserts itself in the martial context of the narrated conflict. The paper concludes that the heroes of the Paraguayan War were common people that, in the face of great suffering, presented an above average behavior, in the sense that the heroism in the person capable of presenting the collectivity the hope and love desired in adverse situations identifies himself, as in this historical example. As for the methodology, this work utilized the hypothetical-deductive method, with historical proceeding.

Keywords: Hero; heroism; circumstances; Paraguayan War; human dimension. 


\section{INTRODUÇÃO}

A história da humanidade se alicerça nos feitos dos homens enquanto parte de seus respectivos grupos. Esses feitos são observáveis e classificáveis por envergadura, sobre eles recaindo também o juízo de valores para definir se são proveitosos ou deletérios para a memória conjunta desses grupos. A partir desse juízo, com uma avaliação positiva, surge, inescapavelmente, a figura do herói.

Ao se trabalhar com a ideia de herói, é compreensível que se recorram às imagens das figuras mitológicas deixadas por gregos e romanos ou aos grandes líderes políticomilitares que preenchem os livros de história. Porém, a questão é mais profunda: a noção sobre o que é e como se manifesta o heroísmo vai além das figuras já capturadas por esse senso imediato.

Aqui, atinge-se o propósito deste trabalho, ao se pretender apresentar uma nova concepção sobre essa figura, permitindo entender como ela pode alcançar mesmo os indivíduos aparentemente mais ordinários, a ponto de identificá-la e inseri-la num episódio histórico importante para o Brasil: a Guerra do Paraguai (1864-1870).

Dessa forma, a estrutura do artigo se alicerçará, em um primeiro momento, na apresentação do conceito tradicional da figura heroica, e na construção de um novo, que embasará a tese central. Então, será apresentada uma síntese dos eventos e fatos ocorridos durante a Guerra do Paraguai, para que se compreenda como a figura construída no primeiro capítulo pode nela se encaixar. Esse encaixe será completado diante da apresentação da dimensão humana que cerca a imagem heroica, e como ela se insere no contexto bélico.

Para a consecução desta pesquisa, valeu-se no método hipotético-dedutivo, mediante revisão bibliográfica, vez que se construiu um conceito para se moldar uma hipótese para análise de um caso particular, diante do encaixe da definição apresentada logo ao início do trabalho no fato histórico descrito. O procedimento de pesquisa foi, naturalmente, o histórico. 


\section{HERÓI}

Todas as civilizações se encaixam na esfera de uma determinada cultura. Essa cultura se alicerça sobre uma memória coletiva, que pode ser definida como a lembrança dos feitos realizados em comum. Esses feitos, agrupados em um todo unívoco, perfazem a trajetória de cada nação por eles representada. Nessa trajetória, é natural que se evidenciem atos individuais de maior envergadura, voltados para o bem ou para o mal. O caso dos primeiros abarca o surgimento da figura que se conhece como herói.

Os dicionários não trazem uma única assertiva para esse conceito. Entre os significados trazidos, pode-se encontrar: 1) "aquele que se distingue por seu valor ou por suas ações extraordinárias"; 2) "Pessoa que se destaca em relação aos demais"; 3) "Aquele que é condecorado por suas ações corajosas, pelo seu caráter magnânimo, por comportamentos altruístas"; e 4) "Quem é capaz de suportar situações adversas sem se abater" (DICIO, 2021). Todas essas assertivas são válidas dentro de seus respectivos limites conceituais, mas este trabalho propõe um passo a mais: a construção de um novo conceito de herói, que se possa amoldar adequadamente dentro da interpretação desta figura na Guerra do Paraguai (18641870).

\subsection{A VIVÊNCIA DAS CIRCUNSTÂNCIAS - A VISÃO HEROICA A PARTIR DE ORTEGA Y GASSET}

A vida impõe a todos os seus limites. As situações de fato em que eles se verificam podem ou não ser limitantes para o desenvolvimento das potencialidades de uma pessoa. Porém, sobre elas, o filósofo espanhol José Ortega Y Gasset (1883-1955) exprime uma de suas antológicas citações: "Yo soy yo y mi circunstancia, y si no la salvo a ella no me salvo yo" (ORTEGA Y GASSET, 1914, p. 43-4).

Para que se entenda esse comentário, faz-se necessária a compreensão do conceito de circunstância dentro da filosofia de Ortega, o que vem elucidado por Carvalho $(2009$, p. 335-6), nos termos:

O conceito de circunstância contempla o entorno que não se resume à paisagem representada pelo ambiente social ou o nós. Este ponto é marcante no

\footnotetext{
1 “Eu sou eu e minha circunstância, e se não salvo a ela, não salvo a mim mesmo" (tradução livre).
} 
raciovitalismo, o entorno ao eu inclui a intimidade representada pelos mecanismos fisiológicos da vida, das leis que regem a alma e pelas expressões do pensamento ou espírito, tudo isto histórico e escondido em cada homem. [...] A intimidade ou o lado de dentro que representa a parcela oculta da vida também circunscreve o eu, como também o envolve a situação exterior, a realidade social, econômica, política, temporal, em resumo cultural onde vivemos. O lado de fora do indivíduo, aquilo que se manifesta para os outros, é expressão do interior que se deixa ser conhecido pelo que aparece fora. $\mathrm{O}$ homem tem, pois um lado de fora e um de dentro e ambos circunscrevem o eu, sendo que o corpo põe à mostra a alma [...]

Sumarize-se, portanto: o ser humano incorpora em si uma série de particularidades, que acabam constituindo a forma como ele se percebe e identifica perante si mesmo e no mundo. Essas particularidades tais como classe social ou local de nascença, podem representar fatores que limitam o homem na vivência de suas capacidades.

O filósofo espanhol, contudo, ensina a amar essas circunstâncias, ao estabelecer que sua reabsorção é o destino concreto do homem (ORTEGA Y GASSET, 1914). Seu raciocínio se completa com interessante observação (ORTEGA Y GASSET, 1914, p. 44-5):

Nada impide el heroísmo-que es la actividad del espíritu-, tanto como considerarlo adscrito a ciertos contenidos específicos de la vida. Es menester que donde quiera subsista subterránea la posibilidad del heroísmo, y que todo hombre, si golpea con vigor la tierra donde pisan sus plantas, espere que salte una fuente ${ }^{2}$.

Chega-se, então, à primeira parte do conceito buscado: o herói é a pessoa que, fundamentalmente, transcende suas circunstâncias, golpeando a terra à espera da fonte, de modo a imprimir uma marca no presente com os seus atos. A compreensão da segunda parte vem a partir do entendimento do porquê desse ato de transcendência.

\subsection{O SENTIDO DA VIDA E O SERVIÇO AO PRÓXIMO - A CONTRIBUIÇÃO DE VIKTOR FRANKL}

Defende-se neste trabalho que a superação das circunstâncias individuais não é um ato que se deve entender isoladamente por si, mas sim uma atitude que precisa vir acompanhada de

\footnotetext{
${ }^{2}$ Nada impede o heroísmo - que é a atividade do espírito -, tanto como considerá-lo apegado a certos conteúdos específicos da vida. É necessário, onde quer que exista a subterrânea possibilidade de heroísmo, que todo homem, se golpeia com vigor a terra em que se pisam as plantas, espere que salte uma fonte (tradução livre).
} 
um sentido intrínseco dado pelo sujeito que a concretiza. Para isso, deve-se compreender a natureza dessa característica.

O psiquiatra austríaco Viktor Frankl (1905-1997) desenvolveu uma abordagem psicoterapêutica chamada logoterapia. Nas palavras de Rodrigues e Barros (2009), essa abordagem se baseia na ideia de que a vida possui um sentido, fundamentando-se no respeito ao ser humano, que seria um ente responsável e capaz de se posicionar perante os condicionamentos da vida.

No que diz respeito não apenas à busca desse sentido, mas seu direcionamento, Frankl (1987, p. 75) assim se manifesta:

\begin{abstract}
Ao declarar que o ser humano é uma criatura responsável e precisa realizar o sentido potencial de sua vida, quero salientar que o verdadeiro sentido da vida deve ser descoberto no mundo, e não dentro da pessoa humana ou de sua psique, como se fosse um sistema fechado. Chamei esta característica constitutiva de "a autotranscendência da existência humana". Ela denota o fato de que ser humano sempre aponta e se dirige para algo ou alguém diferente de si mesmo - seja um sentido a realizar ou outro ser humano a encontrar. Quanto mais a pessoa esquecer de si mesma - dedicando-se a servir uma causa ou a amar outra pessoa - mais humana será e mais se realizará. $O$ que se chama de auto-realização não é de modo algum um objetivo atingível, pela simples razão de que quanto mais a pessoa se esforçar, tanto mais deixará de atingi-lo. Em outras palavras, auto-realização só é possível como um efeito colateral da auto-transcendência-
\end{abstract}

Note-se que a procura advogada por Frankl se encontra atrelada ao serviço dedicado ao próximo. Uma existência humana plena não se resumiria, portanto, à simples satisfação egoísta de suas próprias necessidades. Frankl (1987) defende que a descoberta de sentido para a vida pode se dar de três formas: (1) criando um trabalho ou praticando um ato; (2) experimentando algo ou encontrando alguém; e (3) pela atitude que tomamos em relação ao sofrimento inevitável.

Em relação a esse terceiro aspecto, pode-se dizer que a concepção de Frankl sobre a carga do sofrimento serve como um apontamento de caminho em busca da redenção do sujeito que dele padece. Assim, o indivíduo converte o sofrimento em sacrifício. Veja-se:

Não devemos esquecer nunca que também podemos encontrar sentido na vida quando nos confrontamos com uma situação sem esperança, quando enfrentamos uma fatalidade que não pode ser mudada. Porque o que importa, então, é dar testemunho do potencial especificamente humano no que ele tem de mais elevado, 
e que consiste em transformar uma tragédia pessoal num triunfo, em converter nosso sofrimento numa conquista humana. Quando já não somos capazes de mudar uma situação - podemos pensar numa doença incurável, como um câncer que não se pode mais operar - somos desafiados a mudar a nós próprios (FRANKL, 1987, p. 76).

Complemente-se, pois, o conceito que se pretende trabalhar neste artigo: o herói é aquele que transcende suas circunstâncias por meio do sacrifício, o que faz como forma de dedicar serviço ao próximo. E é nessa transcendência que ele encontra o sentido para a sua vida. Completar essa definição dependerá da fixação do alcance sobre quem é esse "próximo".

O "próximo" a quem e por quem se concretizam os atos do herói é uma figura ampla. Ele pode representar desde um ente querido até o próprio país. Recorde-se aqui que o heroísmo enquanto fenômeno está ligado, fundamentalmente, ao cumprimento de um dever, ato que evidencia um último elemento em sua constituição.

Esse elemento é aquele que abastece a busca de sentido e a superação das circunstâncias do indivíduo: a virtude. Sobre ela, considerada a importância dessa concepção, devem-se dedicar algumas linhas, optando-se por adotar como fundamento a base conceitual que lhe é fornecida pelo ensinamento da Igreja Católica.

\subsection{A VIRTUDE COMO ELEMENTO FINAL DO CONCEITO HEROICO - A PERSPECTIVA DO CATECISMO DA IGREJA CATÓLICA}

O elemento final para a construção do conceito de herói que aqui se pretende defender é dado pelos ensinamentos da Igreja Católica, em virtude não apenas da importância desta instituição, mas também da pertinência e precisão com que trata o tema. A ideia final, portanto, reside na noção de virtude.

De início, recorde-se sua definição trazida pelo Catecismo da Igreja Católica (2017, p. 485): “A virtude é uma disposição habitual e firme para fazer o bem. Permite à pessoa não só praticar atos bons, mas dar o melhor de si. Com todas as suas forças sensíveis e espirituais, a pessoa virtuosa tende ao bem, o procura e o escolhe na prática". 
Não se cingindo ao elemento teológico desse conceito, amplie-se aqui a noção do destinatário do citado "bem". A figura beneficiada pelos atos da pessoa virtuosa varia da família à pátria, em outro conceito amplo. Prossegue o compêndio:

As virtudes humanas são atitudes firmes, disposições estáveis, perfeições habituais da inteligência e da vontade que regulam nossos atos, ordenando nossas paixões e guiando-nos segundo a razão e a fé. Propiciam, assim, facilidade, domínio e alegria para levar uma vida moralmente boa. Pessoa virtuosa é aquela que livremente pratica o bem (CIC, 2017, p. 485-6).

O indivíduo virtuoso é, portanto, aquele que tem as paixões ordenadas. Isso lhe permite a aquisição de uma resistência suficiente para poder superar as adversidades do meio à sua volta. Portanto, conclua-se este-tópico apresentando o conceito definitivo cuja defesa será contextualizada no decorrer do artigo: o herói é aquela pessoa que, impelida pela virtude na busca e defesa de um sentido para sua vida, sacrifica-se sob um ideal de serviço ao próximo, reabsorvendo e transcendendo as suas circunstâncias.

O surgimento desse tipo de personagem é propiciado pela existência de fatos extraordinários, nos quais residem os momentos historicamente propícios para o aparecimento de figuras heroicas, particularmente se esses episódios perfazem acontecimentos históricos importantes na trajetória de uma nação como um todo. No contexto latino-americano, um desses momentos mais determinantes é a Guerra do Paraguai (1864-1870), episódio com importância vital para os países participantes, e no qual a existência e amplitude do heroísmo levam a debates sobre a dimensão humana das figuras de seus participantes com esses atributos. A seguir, será recordada a história do desenvolvimento do conflito, de forma a embasar a tese central.

\section{EVENTOS HISTORICOS DA GUERRA DO PARAGUAI}

A Guerra do Paraguai, somente conhecida por este toponímico no Brasil, visto ser conhecida por Guerra da Tríplice Aliança na Bacia do Prata e por Guerra Grande no Paraguai, foi o maior conflito armado em que as Forças Armadas Brasileiras participaram diretamente, seja pela quantidade de mortos, tempo de duração dos embates e pelas consequências geopolíticas decorrentes. 
A Historiografia, durante o tempo, evocou diversos matizes para compreender o desenrolar dos fatos e explicar as razões para a deflagração do conflito em apreço. Estas visões históricas foram influenciadas pelas tendências acadêmicas dos pesquisadores que as formularam, enfatizando determinado aspecto ou pretendendo apresentar a visão intelectual do autor.

A primeira que apresentamos é aquela descrita logo após a Proclamação da República, período em que militares, veteranos do conflito, estavam no comando da nação ou tinham participação proeminente nas decisões. Esta corrente procurou enaltecer as virtudes heroicas dos combatentes, atribuindo ao expansionismo paraguaio o estopim pela deflagração das hostilidades.

Esses autores enfatizam a nação guarani, um país com características mediterrâneas no coração sul-americano, almejando uma saída para o mar e que, alegando interferências do Brasil no Uruguai, teria tomado medidas de cunho bélico. Tais medidas levaram o Império Brasileiro, a República da Argentina e o Uruguai a unirem esforços para derrotar as intenções de Solano López, o ditador paraguaio, herdeiro político de seu pai, Carlos López, que controlava seu território com mão de ferro.

Essas ideias estão fundadas em acontecimentos plenamente documentados, sendo, portanto, muito fiéis aos ensinamentos positivistas, em voga na época. Esses acontecimentoschave seriam o aprisionamento do navio Marquês de Olinda, a Invasão de Mato Grosso e o ataque a Uruguaiana. Assim, entenderíamos que foram os paraguaios os causadores da guerra.

O aprisionamento do navio Marquês de Olinda ocorreu no dia 12 de novembro de 1864. Este vaso, então sob o comando de Manoel Luiz da Silva Souto, foi capturado no Rio Paraguai, a montante de Assunção, antes de cruzar a fronteira com o então Mato Grosso. Entre os capturados, estava o nomeado presidente desta província brasileira. Entre os motivos alegados estão a tentativa de Solano López em distrair os brasileiros da campanha destes contra o Uruguai e a informação, não confirmada, que a embarcação transportava armas e tesouros valiosos. 
Os tripulantes, passageiros e oficiais foram capturados e encarcerados. Os últimos sofreram torturas, fome e falta de cuidados, o que acarretou na morte de todos, menos dois, libertados em 1869, com o avanço das tropas aliadas sobre o Paraguai.

Por sua vez, a invasão de Mato Grosso ocorreu entre dezembro de 1864 e abril de 1868, ou seja, na fase inicial do conflito, embora antes da declaração oficial de guerra, ocorrida em 13 de dezembro de 1864. Feita por um Corpo de Exército paraguaio, realizou-se quase simultaneamente com a invasão da província argentina de Corrientes e do Rio Grande do Sul. Pela superioridade numérica e a fraca defesa brasileira, teve fácil sucesso (TOLENTINO, 1986).

Esse avanço foi dividido em duas colunas. A primeira, chamada de Ocidental, subiu o Rio Paraguai, ocupando o Forte Coimbra, após luta, em 20 de dezembro de 1864. Corumbá, abandonada por sua guarnição, que se dirigira para Cuiabá, foi ocupada em 02 de janeiro de 1865. Esta cidade foi reconquistada em 13 de junho de 1867 após campanha conduzida pelo General Antônio Maria Coelho. Essa reconquista foi efêmera, pois uma epidemia de varíola assolou a tropa brasileira, obrigando-a a, novamente, deixar a localidade, reocupada pelos paraguaios em 23 de julho de 1867, ali permanecendo até o desfecho da Batalha de Humaitá, em 1868, ocasião em que Solano Lopez determinou o abandono do Mato Grosso, incluindo o Forte Coimbra e o Morro da Marinha, ponto artilhado (TOLENTINO, 1986).

A outra coluna, a Oriental, iniciou a campanha por terra, partindo de Concepcion em 26 de dezembro de 1864, atacando a Colônia Militar de Dourados, onde enfrentaram heroica defesa por parte do Tenente Antônio João Ribeiro, e seguiram em direção à Cuiabá, passando por Miranda, Nioaque e Coxim. Digna de nota é a participação indígena nessa ocupação. Enquanto Kadiweos, Terena e Quiniquinaus apoiaram os brasileiros, protegendo os refugiados, proporcionando-Ihes comida, apoio logístico e de inteligência, os Guató, do Pantanal, aliaram-se, ainda que temporariamente, aos paraguaios. Também relacionada com a invasão ao Mato Grosso, especificamente a Coluna Oriental, está a célebre "Retirada da Laguna", evento ensejador do livro homônimo escrito por Alfredo D’Escragnole Taunay, onde é relatada a campanha conduzida por uma força brasileira, que partira de São Paulo (CAMPESTRINI e GUIMARAES, 1991).

A invasão ao Rio Grande do Sul e da província argentina de Corrientes ocorreu entre 10 de junho e 18 de setembro de 1865, quando Solano López, tentando forçar os brasileiros a 
se retirarem da guerra em condições favoráveis ao Paraguai, determina a incursão. A tropa paraguaia estava sob o comando de Antônio Estigarribia e de Pedro Duarte. As colunas guaranis seguiram o curso do Rio Uruguai durante a incursão. Duarte conquista Paso de los Libres em 02 de agosto de 1865 e, dois dias depois, Estigarribia ocupa Uruguaiana. Contudo, problemas logísticos e falta de reforços ocasionaram a rendição paraguaia ao Conde de Porto Alegre, Manoel Marques de Souza, encerrando a campanha no sul do Brasil (VASCONSELLOS, 1962).

Este entendimento da História sobre a Guerra do Paraguai encontrou oposição quando Chiavenato (1979) escreveu uma obra intitulada "Genocídio Americano: A Guerra do Paraguai". Para esse autor, a guerra teria razões de controle hegemônico mundial, na medida em que o Paraguai apresentaria condições socioeconômica, como baixas taxas de analfabetismo, condições industriais autônomas e liderança política soberana, capazes de proporcionar mecanismos de enfrentamento ao centro do poder mundial à época, a Inglaterra vitoriana.

A Historiografia nacional teria sido abalada com essa publicação. Queiróz (2011, p. 12), enfatiza que;

O livro causou grandes discussões sobre a historiografia nacional da guerra do Paraguai, desagradando os militares, principais representantes da história oficial sobre aquele conflito. Afinal, Chiavenato superava a descrição factual das batalhas; discutiu a formação histórica, social e econômica do Paraguai; denunciou os interesses da guerra; impugnou pontos cruciais das narrativas oficiais e oficiosas; desconstruiu os grandes heróis militares nacionais; mostrou o sofrimento do povo como outro lado da guerra; denunciou a ação das tropas imperiais no Paraguai, o excesso de violência, os crimes de guerra, as deserções. Desconstruiu a retórica sobre os Voluntários da Pátria e os grandes feitos do exército imperial, apresentou um novo Duque de Caxias, um novo Conde d 'Eu, e apresentou ao Brasil, sobretudo, um novo Paraguai, muito diferente da visão nacional- patriótica [...]

Ainda segundo Queiróz (2011), o trabalho teria sofrido grande rejeição por parte da historiografia tradicional, cuja produção seria capitaneada pelo Exército, pela Academia Brasileira de Letras e por parte da imprensa. Segundo ela, a censura impedia novos olhares históricos sobre assuntos ligados ao poder mundial, referenciando outra obra de Chiavenato, "A Guerra do Chaco". Este posicionamento teria dominado a produção científica histórica ao longo da década de 80 do século XX até sofrer oposição. Este questionamento à essa corrente 
se dá por diversas questões, que na essência fogem ao objetivo deste trabalho, mas de grande importância para a compreensão de como a guerra aflige as pessoas mais que as instituições. Doratioto (2002) enfoca sua produção mais em relatórios estatísticos do que em interesses políticos. Contudo, o próprio Doratioto $(2009$, p. 8) continua afirmando que toda produção intelectual está contextualizada no meio político onde foi redigida:

A Nueva Historiografia sobre la Guerra de la Triple Alianza ou Interpretação Sistêmica Regional está isenta de ideologia? Claro que não. Sabe-se, muito bem, que toda produção intelectual carrega consigo valores da época em que foi escrita e do seu autor. A Nueva Historiografia emerge no contexto do fim das ditaduras no Cone Sul e, no plano mundial, do término da Guerra Fria. Esses acontecimentos levaram à abertura de arquivos; a maior liberdade acadêmica e à oxigenação ideológica, criando as condições para a ousadia intelectual por parte dos historiadores, que passaram a estudar novos objetos e questionar antigas interpretações que se apoiavam em precária base documental. Foi a redemocratização dos países que vivenciaram a Guerra do Paraguai que permitiu superar o revisionismo simplificador.

O primeiro aspecto desse revisionismo seria a constatação de que Solano López efetivamente expôs sua população a um conflito com um gigante 22 vezes maior do que ele, em especial quando o torno uma "Guerra Total", ocasião quando toda a população está envolvida, não apenas as forças militares.

Continuando nessa nova forma interpretativa, outro viés polêmico é a percepção de que o subdesenvolvimento paraguaio não poderia ser atribuído exclusivamente à guerra, que por óbvio causa a ruína de nações, mas encerrada há 150 anos. Mesmo antes do conflito a nação tinha característica rurais, com fraca liberdade econômica. Desta forma, sua pobreza não seria somente decorrência dos embates, mas também da forte instabilidade política que por lá vigorou durante o século XX.

Também a influência decisiva para a deflagração do conflito atribuída à Inglaterra não parece se confirmar. Edward Thornton, representante inglês da época, até tentou intervir para o apaziguamento da situação, e que os eventos se resolvessem de forma diplomática. Importante ser dito que, no momento da deflagração do conflito, Brasil e o Reino Unido viviam momentos diplomáticos tensos, culminando com a Questão Christie (DORATIOTO, 2002).

A própria situação brasileira não melhorou em nada com a guerra. 0 país ficou endividado, o movimento abolicionista foi intensificado, minando as bases da oligarquia rural 
escravagista, e a indenização exigida ao Paraguai como reparação nunca foi paga. A moderna História Demográfica também questiona os dados da guerra, alegando não existir base estatística para se afirmar números, o que refutaria um projeto de genocídio perpetrado pela Tríplice Aliança. Ao certo, é que as guerras são feitas por pessoas e que a Guerra do Paraguai forneceu personagens para o panteão heroico republicano, composto, sobretudo por militares participantes deste embate.

Das fileiras imperiais, o Exército tirou aquele que seria seu patrono, cujo nome representa a própria grandeza da força terrestre nacional: Caxias. Nascido Luís Alves de Lima e Silva, no atual município de Duque de Caxias, então chamado Porto Estrela, província do Rio de Janeiro, em 25 de agosto de 1803, tem no seu aniversário comemorado o Dia do Soldado. Assentou praça aos cinco anos de idade e lutou em diversos conflitos internos, destacando-se na Balaiada, no Maranhão, onde recebeu a alcunha de "O Pacificador". Comandou as forças da Tríplice Aliança após a saída de Bartolomé Mitre, reorganizando a tropa e dando-lhe novo ânimo. Foi o único brasileiro a receber o título nobiliárquico de duque, o mais alto na nobreza. Outros nomes aparecem também em destaque no meio castrense, como o de Osório, o Marquês do Herval, vencedor da Batalha de Tuiuti, e do Conde de Porto Alegre, que derrotou os paraguaios no Rio Grande do Sul (ALMEIDA, 1961).

A Armada Imperial, antigo nome da Marinha do Brasil, também extraiu da Guerra do Paraguai aquele que simbolizaria o poder naval: Tamandaré, notável estrategista, que observara do perigo que avizinhava o Mato Grosso nos prelúdios da guerra.

Nome de batismo de diversas embarcações brasileiras ao longo da História, o Almirante Barroso é mais um dos heróis nacionais ligados à Guerra do Paraguai. Vencedor da Batalha Naval do Riachuelo, marco divisor do conflito, evento definidor do controle fluvial indispensável para a consecução das atividades em terra por parte dos aliancistas, em especial pela quase inexistência de estradas na região conflituosa, Barroso é visto como objetivo a ser alcançado pelos marinheiros.

Do aqui apresentado até agora, percebemos que a Guerra do Paraguai foi um nascedouro de heróis nacionais, e que essas personalidades foram pessoas, seres humanos. Daí a importância de vermos qual a dimensão humana destes expoentes. 


\section{A DIMENSÃO HUMANA DO HERÓI}

O conceito de humanidade vem sendo discutido ao longo da História humana por diversas áreas: filosofia, biologia, antropologia, teologia e etc. Pelo conceito do Dicionário de filosofia, define-se a humanidade pela História e pela cultura, aspectos abrangentes que estabelecem valor à formação do ser humano enquanto ser histórico que é. Diante disso, temos:

\footnotetext{
Humanidade. Hist. Cult. 1) Termo usado sobretudo em quatro sentidos: a) essência ou natureza humana, isto é, aquilo que faz que um homem seja homem; b) solicitude do homem pelo seu semelhante, ou filantropia em sentido amplo, abrangendo vasta gama de formas; c) processo de formação do homem, de humanização (a Paideia dos Gregos); d) gênero humano, ou conjunto de todos os homens [sic] (DICIONÁRIO DE FILOSOFIA, s/d)
}

Estabelecido o conceito de humanidade segundo o Dicionário de Filosofia, nos voltamos à dimensão humana segundo Alvarenga (2016), que considera o desenvolvimento do ser humano abrangente quanto à sua complexidade. Segundo ele, as dimensões humanas física, afetiva, social, intelectual e espiritual, "tendem a ser o conjunto de elementos que possibilitam as pessoas se sentir felizes, tornando necessário buscar garantir o desenvolvimento integral do ser humano" (ALVARENGA, 2016, s/p), o que nos leva à reflexão acerca das características de um ser humano comum que realiza feitos extraordinários, recebendo, com isso, o título de herói.

Pela perspectiva de Alvarenga (2016), as dimensões humanas podem ser mais ou menos desenvolvidas em cada indivíduo, o que leva certas pessoas a se tornarem excepcionalmente empáticas em determinadas situações. Nas palavras do autor:

A dimensão afetiva e a dimensão social envolvem diretamente as relações que se estabelecem com os outros circunstancialmente na rua, na escola, no parque, na praça, no shopping, no trabalho, numa viagem, na comunidade religiosa. (ALVARENGA, 2016, s/p)

Ao abordarmos o contexto bélico em que se insere o herói da vida real, podemos afirmar que, de acordo com a reflexão de Alvarenga (2016), suas dimensões afetiva e social são superdesenvolvidas, fornecendo ao ser humano comum o impulso à realização de grandes feitos para beneficiar seus companheiros, os inocentes que são atingidos por situações hostis ou, até mesmo, em prol da causa pela qual se luta. 
Ainda conforme a análise do autor, as situações a que está sujeito o indivíduo que se destaca, estão diretamente relacionadas à sua natureza, no entanto, no extremo oposto do desenvolvimento de suas dimensões sociais e afetivas. Alvarenga (2016, s/p ) afirma que:

Não é possível ignorar que muitas expressões de violência, preconceitos e discriminação, geralmente ocorrem em relações sociais estabelecidas sem o desenvolvimento da dimensão afetiva, de modo que julgamentos desrespeitosos e incompreensão tornam-se infelizmente comuns.

Acerca dessa premissa, a dimensão humana do herói já havia sido desenvolvida no homem comum, estando latente em sua personalidade, o que nos leva à observação de Frankl (1991, s/p ) de que "o heroísmo está na atitude, por assim dizer". O herói em contexto de guerra se vê, a partir da situação vivenciada, em posição de enfrentá-la a partir de sua formação humana individual, se colocando a favor do coletivo devido à sua reação interior diante dos acontecimentos.

Frankl (1991) ressalta que o ser humano em sofrimento se vê diante de dois caminhos: sofrer e silenciar ou aprender a sofrer. Para melhor compreensão, nos voltemos sobre a concepção do autor acerca do significado do sofrimento, conforme segue:

[...] a prioridade permanece com a mudança criativa da situação que nos faz sofrer. Mas realmente superior é o saber como sofrer, quando se faz necessário. E há evidências empíricas de que - literalmente - o "homem comum" é exatamente da mesma opinião. Pesquisas de opinião pública da Áustria revelaram recentemente que aqueles que atraíam a maior estima e consideração entre a maioria dos entrevistados não eram os grandes artistas, cientistas, estadistas ou esportistas, mas aqueles que eram capazes de atravessar experiências difíceis com suas cabeças erguidas (FRANKL, 1991, s/p).

Destaca ainda o referido autor (1991) que o sofrimento não é motivo de orgulho para o ser humano, mas sim, como vimos anteriormente, a atitude diante do sofrimento faz do homem comum, extraordinário. A admiração coletiva que alcança este homem que adapta suas reações, evidenciando suas principais dimensões humanas no enfrentamento das situações adversas, é aquele que será tido como um herói sob os olhares da opinião pública.

Observa também que, "na verdade, as oportunidades de agir de modo apropriado, as potencialidades para realizar um sentido, são afetadas pela irreversibilidade das nossas vidas" (FRANKL, 1991, s/p), ou seja, em ambiente bélico, não há nenhuma mudança quanto 
ao contexto em que o homem se encontra, há apenas atitudes a serem modificadas para que seja possível minimizar os efeitos causados pelas circunstâncias vivenciadas.

\subsection{TERRITORIALISMO E A REPRESENTAÇÃO DO HERÓI}

Para abranger a essência do herói, as ações daqueles que lutaram durante a Guerra do Paraguai serão observadas, delineando as principais características do ser humano extraordinário que, a partir do anseio que o move para o auxílio do outro em ambiente bélico, passa a ser reconhecido com o título. No entanto, pretendendo compreender a dimensão humana do herói, entenda-se, primeiramente, o contexto.

A Guerra do Paraguai, segundo Silva (2018), tem suas causas centradas no processo de formação das nações platinas no contexto da segunda metade do século XIX. Cada nação possuía seus interesses econômicos e políticos, e a defesa desses interesses causou o choque entre o Paraguai e Brasil, Argentina e Uruguai. Segundo o autor:

[...] o Brasil tinha como grande interesse garantir o seu direito de livre navegação pelos rios da Bacia Platina, sobretudo pelo Rio Paraguai, por ser a única forma de o Rio de Janeiro manter contato com a capital de Mato Grosso, Cuiabá (não havia naquela época estradas por terra que ligavam Cuiabá ao restante do Brasil) (SILVA, $2018, s / p)$

Contextualizando, dessa forma, os motivos da Guerra do Paraguai, pode-se identificar, no excerto retirado do texto de Silva (2018), que as defesas de território eram fundamentais para cada uma das nações envolvidas, independente do interesse individual destas. Por território, entretanto, não se compreenda apenas o espaço concreto. A territorialidade é complexa e aprofunda-se nas necessidades humanas.

O conceito de territorialidade é atribuído à etologia animal no "sentido da ênfase da força de apropriação exclusiva do espaço" (BARCELLOS, 1995, p 46). Na concepção de Sodré (1988, p. 13) , concebe-se os "regimes de relacionamento, relações de proximidade e distância". Na perspectiva das ciências humanas, a noção de território é ampliada pela incorporação da dimensão simbólica do espaço físico e concreto, gerando o sentimento de posse e necessidade de defesa. 
Para Mesquita (1995), as pessoas vivem a territorialidade sem ter clara consciência da sua territorialidade individual, já que esta não assume limites visíveis no território concreto e tampouco contornos definidos nos sentimentos de indivíduos e grupos. A territorialidade pode ser entendida como projeção de nossa identidade sobre o território.

Mesquita (1995) distingue várias formas de territorialidade, sendo que destaca: territorialidade familiar, quando no território atualizamos pela identidade, antigos sentimentos de emulação, competição ou solidariedade vividos no território familiar; de senhoril, quando se atualizam e se expressam raízes de posse e poder autoritário ou manipulador, fundamentando o sentimento de pertença territorial e as condutas direcionadas a um uso político do território; e territorialidade cultural, que, por sua vez, é aquela que emerge das manifestações de usos, costumes e linguagem.

Na concepção analisada por Hall (1966), a territorialidade se define como o comportamento característico adotado por um organismo para tomar posse de um território, defendendo-o contra os membros da sua própria espécie. Ela existe também entre os seres humanos, que inventaram numerosas maneiras de defenderem aquilo a que chamam a sua terra, o seu solo ou seu espaço, entre elas, a própria guerra. A territorialidade constitui um sistema de comportamentos fundamentais próprios de todos os organismos vivos, incluindo o homem.

A reflexão acerca do territorialíssimo nos leva a outro aspecto deste estudo: o surgimento do herói em tempos de guerra. Para esta análise, é necessário o retorno aos principais conceitos sobre a figura do herói, sua função na sociedade e suas características específicas, que o tornam especial, inspirador e fundamental para a configuração social. Dito isto, a exposição da dimensão humana do herói se torna passível de investigação.

\subsection{A DIMENSÃO HUMANA DO HERÓI FRENTE À GUERRA}

O herói pode ser visto como um homem de grandes qualidades, cujos atributos se destacam dos demais e suas ações justificam a alcunha de herói. Sendo assim, será traçado o perfil do herói e sua composição, além de expor a análise da contribuição da figura do herói como representação de esperança, amor e virtudes. 
Segundo Galindo (2019), na sociedade grega, cuja filosofia serviu de alicerce para o desenvolvimento do conhecimento ocidental, o herói situava-se na posição intermediaria entre os deuses e os homens, sendo, em geral, filho de um Deus e de uma mortal (como por exemplo, Hércules e Perseu), ou vice-versa (Aquiles). Em decorrência deste fato, curiosamente, para os gregos antigos o herói tinha uma dimensão semidivina. Ou seja, ele era um ser que carregava em si atributos divinos e terrenos ao mesmo tempo. Galindo (2019, s/p) destaca ainda:

[...] o propósito maior de suas ações procurava atuar no sentido de unificar estes dois planos. Resulta daí a origem dos seus poderes extraordinários e dos seus feitos épicos com reflexos no mundo terreno; e, consequentemente na psiquê humana.

Diante da explanação do autor, os feitos épicos do herói mitológico são decorrentes de grande poder que sua constituição lhe concede, que é a filiação de um deus e uma mortal e vice-versa. No entanto, quando falamos de personagens históricos que se tornaram representações dos heróis terrenos, Eliade, (1991, s/p) apud Gomes; Andrade (2009, s/p) ressaltam:

[...] que essa retomada dos diversos simbolismos não é uma descoberta inédita do mundo moderno, tendo em vista que o símbolo, enquanto instrumento de conhecimento, era uma orientação presente na Europa até o século XVIII, além de se fazer presente em culturas extra-européias, mesmo naquelas consideradas arcaicas e primitivas.

Gomes e Andrade (2009) afirmam ainda que os simbolismos estão relacionados ao inconsciente pessoal, uma vez que estes inserem conteúdos mentais adquiridos durante a vida do indivíduo e que foram esquecidos ou reprimidos, enquanto que o inconsciente coletivo é uma estrutura herdada comum a toda a humanidade composta dos arquétipos. Uma elaboração derivada destes arquétipos povoa todos os grandes sistemas mitológicos e religiosos do mundo. Sobre a existência do arquétipo, refletindo seus impactos na sociedade, Jung (2000, p.53) afirma:

O conceito de arquétipo, que constitui um correlato indispensável da idéia do inconsciente coletivo, indica a existência de determinadas formas na psique, que estão presentes em todo tempo e em todo lugar [sic]. 
Desta forma, temos a figura do herói como representação da necessidade de expressão de esperança e amor em situações adversas do seu tempo. Segundo Campbell (1997), a primeira tarefa do herói consiste em retirar-se da cena mundana dos efeitos secundários e iniciar uma jornada pelas regiões causais da psique, onde residem efetivamente as dificuldades, para torná-las claras, erradicá-las em favor de si mesmo (isto é, combater os demônios infantis de sua cultura local) e penetrar no domínio da experiência e da assimilação, diretas e sem distorções, daquilo que Jung (2000) denominou "imagens arquetípicas" .

O herói em contexto de guerra enquadra-se na imagem arquetípica, uma vez que desafia o horror da guerra em defesa de sua pátria, seus conterrâneos e o próprio território. A figura do herói representa esperança e inspira àqueles que não possuem as habilidades e capacidade dos heróis no enfrentamento das situações adversas, a se manterem confiantes e, em grande parte, se convencerem de que podem contribuir com ações heroicas igualmente válidas para a sociedade.

As ações de heroísmo incluem virtudes como a persistência, a resiliência, a fé, a força de vontade, a determinação, a paciência, a justiça, a empatia, o altruísmo, e a capacidade de auto sacrifício. Galindo (2019) lembra que, além das virtudes, é importante mencionar que o verdadeiro herói deverá sempre ser guiado por ideais nobres e altruístas.

Os feitos do herói sempre demonstram sendo de coletividade, coragem, fraternidade, liberdade, sacrifício, justiça, moral; e, finalmente, a paz em todo o planeta. Segundo Galindo (2019), seus horizontes de atuação estão sempre pautados em ações voltadas para o bem de toda a humanidade e não para os próprios interesses. Essa representatividade dos anseios da sociedade é fundamental para que, individualmente, não se perca a esperança de dias melhores.

\section{CONSIDERAÇÕES FINAIS}

O Trabalho foi realizado com a finalidade de se identificar o que seria um herói; como a Guerra do Paraguai apresentou pessoas para montar o arquétipo deste conceito; e qual seria a dimensão humana destes. Para tanto, foi realizada revisão bibliográfica, procurando visualizar, inicialmente, como a literatura científica entende aqueles que, de uma forma ou outra, realizam atos incomuns. Passado este aspecto, buscaram-se, no material histórico já 
produzido sobre o conflito em comento, as diversas formas abordadas pela História com relação ao tema, procurando identificar quais suas tendências. Por fim, investigou-se o que é e qual o entendimento de dimensão humana em situações conflituosas.

Ficou patente que as situações podem estimular diferentemente as pessoas, apresentando situações nas quais alguém, por suas qualidades pessoais, se sobressai e tornase exemplo para a sociedade em que está inserido. Esta pessoa, cuja definição não pode se encontrar facilmente em dicionários com verbetes, é o herói, cuja particularidade principal é a de observar um obstáculo e transpô-lo. Mas essa virtude em superar dificuldades, per si, não tornaria alguém uma pessoa com características heroicas. Para se atingir este patamar, o empreendedor deve dedicar este esforço em prol do coletivo, podendo este ser a pátria.

Deste modo, um momento no qual se verifica a ocorrência do heroísmo neste viés é a guerra, quando cidadãos envidam todas as suas forças para a vitória de sua nação no campo de batalha. Como demonstrado, a Guerra do Paraguai, no caso da História Brasileira, é um exemplo bem contundente. Do apresentado, a primeira corrente historiográfica apresentaria os militares combatentes de forma mais próxima deste conceito de herói, ao enaltecer a participação destes na defesa nacional contra um invasor. Por sua vez, a corrente mais vinculada ao envolvimento inglês na deflagração do conflito apresenta os brasileiros como algozes e os paraguaios como vítimas, numa inversão de papéis. Por sua vez, os estudiosos mais recentes não apontam culpados e inocentes nessa contenda.

De qualquer forma, independente do lado de observação, os heróis na Guerra do Paraguai foram pessoas comuns, que diante de grande sofrimento apresentaram um comportamento acima da média esperada para a sociedade, realizando atos extraordinários, tendo-se em mente sempre que este embate bélico refletiu a disputa de territorialidades, ocasião em que os seres humanos enfrentam seus iguais para deter o controle sobre algum território considerado seu por grupos rivais. Assim, o sofrimento forjaria a identificação do herói como uma pessoa capaz de apresentar à coletividade a esperança e o amor desejados em caso de situações adversas.

Do anteriormente descrito, observamos que o herói é todo aquele personagem que possui virtudes incomuns à sociedade e que, em momentos de extrema dificuldade, atende 
ao entendido como humanidade no sentido de auxiliar o próximo, ajudando-o, pondo sua vida em função dos demais.

\section{REFERÊNCIAS}

ALMEIDA, Antônio da Rocha. Vultos da pátria: os brasileiros mais ilustres de seu tempo. Rio de Janeiro: Globo, 1961.

ALVARENGA, Mary. Dimensões humanas. SlidShare, 2016. Disponível em <https://pt.slideshare.net/Alvarenga-48/dimenses-humanas> Acesso em 02 jul.2021.

BARCELLOS, Jorge A. S. Territórios do cotidiano: introdução a uma abordagem teórica contemporânea. In :MESQUITA, Z ; BRANDÃO, C.R. (Orgs) Territórios do cotidiano: uma introdução a novos olhares e experiências. Porto Alegre Ed. Universidade/UFRGS, Santa Cruz do Sul Ed. Umversidade/UNISC, 1995 p 40-48

CAMPBELL, Joseph. O herói de mil faces. Tradução Adail Ubirajara Sobral. São Paulo: CULTRIX/ PENSAMENTO, 1997, Edição 10a․ Disponível em $<$ https://projetophronesis.files.wordpress.com/2009/08/joseph-campbell-o-heroi-de-milfaces-rev.pdf> Acesso em 20 mai.2021.

CAMPESTRINI, Hildebrando e GUIMARÃES, Acyr Vaz. História de Mato Grosso do Sul. Campo Grande: Assembleia Legislativa de Mato Grosso do Sul, 1991.

CARVALHO, José Mauricio de. O conceito de circunstância em Ortega y Gasset. Revista de Ciências Humanas, v. 43, n. 2, p. 331-45, 2009.

CATECISMO DA IGREJA CATÓLICA. 19.ed. São Paulo: Loyola, 2017.

CHIAVENATO, Júlio José. Genocídio americano: a Guerra do Paraguai. São Paulo: Brasiliense, 1979.

DORATIOTO, Francisco. História e Ideologia: a produção brasileira sobre a Guerra do Paraguai, Nuevo Mundo Mundos Nuevos [En ligne], Colloques, mis en ligne le 13 janvier 2009, consulté le 20 mai 2021. URL : http://journals.openedition.org/nuevomundo/49012 ; DOI : https://doi.org/10.4000/nuevomundo.49012. P. 1 - 9.

DORATIOTO, Francisco. Maldita Guerra; nova história da Guerra do Paraguai. São Paulo: Companhia das Letras, 2002.

Dicionário de Filosofia. Humanidade. $\mathrm{s} / \mathrm{d}$. Disponível em $<$ https://sites.google.com/view/sbgdicionariodefilosofia/humanidade> Acesso em 01.07.2021.

FRANKL, Viktor Emil. Em busca de sentido: um psicólogo no campo de concentração. Tradução de Walter O. Schlupp e Carlos C. Aveline. São Leopoldo: Sinodal, 1987.

FRANKL, Viktor Emil. Em busca de sentido: um psicólogo no campo de concentração. Petrópolis: Vozes, 1991. RAFAEL, Z. A. Disponível em <https://files.cercomp.ufg.br/weby/up/58/o/Em_Busca_de_Sentido_-_Viktor_Frankl.pdf> Acesso em 02 jul.2021. 
GALINDO, Toni. Precisamos de heróis ou de referências? Revista administradores.com, publicação online, 2019. Disponível em <https://administradores.com.br/artigos/precisamosde-her\%C3\%B3is-ou-de-refer\%C3\%AAncias> Acesso em 25 mai.2021.

GOMES, Vinícius Romagnolli Rodrigues. ANDRADE, Solange Ramos de. Mitos, símbolos e o arquétipo do herói. Cesumar, v. 11, n. 2, 2009, p. 139-147. Disponível em $<$ https://periodicos.unicesumar.edu.br/index.php/iccesumar/article/view/1271> Acesso em 20 mai.2021.

HALL, Edward T. A dimensão oculta. Lisboa Relógio D’Água, 1966.

HERÓI. In: DICIO, Dicionário Online de Português. Porto: 7Graus, 2021. Disponível em <https://www.dicio.com.br/heroi/>. Acesso em 12 jul.2021.

JUNG, Carl Gustav. Os arquétipos e o inconsciente coletivo. Tradução Maria Luíza Appy, Dora Mariana R. Ferreira da Silva. - Petrópolis, RJ : Vozes, 2000. Disponível em $<$ https://conexoesclinicas.com.br/wp-content/uploads/2015/05/jung-c-os-arquetipos-e-oinconsciente-coletivo.pdf> Acesso em 21mai.2021.

MESQUITA, Zilá. Do território à consciência territorial. In: MESQUITA, Z.; BRANDÃO, C.R. (Orgs). Territórios do cotidiano: uma introdução a novos olhares e experiências Porto Alegre Ed. Universidade/UFRGS, Santa Cruz do Sul. Ed. Universidade/UNISC, 1995. p. 76-92.

ORTEGA Y GASSET, José Ortega y. Meditaciones del Quijote. Madrid: Imprenta Clásica Española, 1914

QUEIRÓZ, Silvânia de. História e historiografia: revisando a obra "Genocídio americano: a guerra do Paraguai", de J.J. Chiavenato. Anais do XXVI Simpósio Nacional de História ANPUH • São Paulo, julho 2011, p. 1 - 16.

RODRIGUES, Larissa Assunção; DE BARROS, Lúcio Alves. Sobre o fundador da logoterapia: Viktor Emil Frankl e sua contribuição à psicologia. Revista EVS-Revista de Ciências Ambientais e Saúde, v. 36, n. 1, p. 11-31, 2009.

SILVA, Daniel Neves. Causas da Guerra do Paraguai. Revista Mundo Educação, 2018. Disponível em <https://mundoeducacao.uol.com.br/historiadobrasil/causas-guerraparaguai.htm> Acesso em 26 jun.2021.

SODRÉ, Muniz. O terreiro e a cidade. Petrópolis: Vozes, 1988.

TOLENTINO, Teresinha Lima. Ocupação do Mato Grosso antes e depois da Guerra da Tríplice Aliança. São Paulo: Fundação Escola de Sociologia e Política da São Paulo, 1986.

VASCONSELLOS, Victor Natalicio. Lecciones de Historia Paraguaya. Assunção: Livraria Freitas Bastos, 1962. 